\title{
Frailty and its quantitative clinical evaluation
}

\author{
${ }^{1} \mathrm{P}$ Moorhouse, ${ }^{2} \mathrm{~K}$ Rockwood \\ ${ }^{1}$ Assistant Professor of Medicine (Geriatric Medicine) Consultant Physician; ${ }^{2}$ Professor of Medicine (Geriatric Medicine E Neurology) \\ Consultant Physician, Queen Elizabeth II Health Sciences Centre, Department of Medicine, Dalhousie University, Halifax, Canada
}

\begin{abstract}
Frailty is a progressive physiological decline in multiple organ systems marked by loss of function, loss of physiological reserve and increased vulnerability to disease and death. Frail older adults are vulnerable to poor health outcomes including an increased risk of disability, social isolation and institutionalisation. With the advances in understanding of the physiological underpinnings and clinical measurement of frailty over the past decade, opportunities both to streamline and quantify the clinical measurement and care planning associated with frailty have emerged. Such tools allow clinicians to recognise and quantify frailty in order to understand a patient's vulnerability to poor health outcomes in a way that chronological age does not provide. Clinical research into outcomes associated with frailty in specific settings is ongoing and will be instrumental to the provision of appropriate care of older adults in the future.
\end{abstract}

\author{
Correspondence to K Rockwood, \\ Centre for Health Care of the \\ Elderly, Veterans' Memorial \\ Building, Capital District Health \\ Authority, I42 I-5955 Veterans' \\ Memorial Lane, Halifax, \\ Nova Scotia, B3H 2EI Canada
}

tel. 0019024738687

e-mail Kenneth.Rockwood@Dal.Ca

KEYWORDS Frailty, aged, frailty index, geriatric assessment

DECLARATION OF INTERESTS With colleagues, Professor Rockwood has applied to various Canadian funding schemes to commercialise a version of the frailty index based on a comprehensive geriatric assessment. To do so, he has helped found a company called Videx Canada. He also received travel costs to Athens from IAGG,WHO and SFGG.

\section{OVERVIEW}

Although the concept of frailty is well-recognised in geriatric medicine, its definition has historically been more elusive. For many years working definitions have emphasised the complex interplay of factors (physiological, medical, sometimes environmental, and even social) that result in an impaired ability to respond to stress. In consequence, what might be an insult that would result in a reversible impairment in a fit person could cause permanent disability in a frail person.'

These definitions share the idea that frailty is multifactorial and that it entails a response to disease that is markedly different from that of more fit adults of the same age. An understanding of the importance and clinical manifestations of frailty may best be achieved through analogy (Figure I).

In general, frailty can be viewed either as a syndrome or as a state. However it is viewed, after Galileo, an important step in advancing our understanding of frailty is to quantify what is quantifiable, and to make quantifiable what is not so.

\section{FRAILTY AS A SYNDROME: THE FRAILTY PHENOTYPE}

There have been considerable advances in the understanding of the physiological underpinnings, measurement and predictive validity of the frailty construct in the last ten years or so. A frailty phenotype (Table I) was proposed in $200 \mathrm{I}$ to suggest that an individual is frail if he/she experiences three or more of the following five symptoms: slowness, weight loss, impaired strength, exhaustion and low physical activity/ energy expenditure. ${ }^{2}$ This definition has been extensively studied and shows predictive validity for poor health outcomes across a wide range of illnesses and procedures. Even so, the phenotype definition for frailty can be insensitive and non-specific (especially in relation to Parkinson's disease, dementia and some cancers). ${ }^{3}$ It does not readily grade degrees of frailty. This is an important consideration, in as much as the construct of frailty was motivated in large measure by the heterogeneity in the risk of adverse outcomes of people of the same age; having marked heterogeneity of risk in people who are frail can therefore be a problem, but one helped by staging frailty. Finally, there is ongoing disagreement about the number and nature of items that should be included, with proposals both to reduce and to increase (especially cognition and affect) the number of items considered. ${ }^{4}$

\section{FRAILTY AS A STATE: THE FRAILTY INDEX}

The Frailty Index $(\mathrm{Fl})$ takes a contrasting view to frailty as a syndrome, seeing frailty instead as a state of vulnerability that arises in relation to the accumulation of health deficits. ${ }^{5}$ People with few deficits are relatively fit; those with many are relatively frail. Studies which have used an FI show frailty as a quantifiable attribute 
Systems can be complex or simple. A toaster is an example of a simple system. It performs one function. When it fails, it is disposed of and replaced entirely. In contrast, a jet airplane is a complex system. It performs several tasks, including transportation, navigation, meal service, in-flight entertainment, safety, etc. In any commercial flight, a number of human or mechanical errors or failures occur, but because of inherent redundancy (i.e. backup equipment, regular safety checks, and maintenance), you as the passenger still get to your destination blissfully unaware of any problems.

Humans are like jet airplanes. When we are young, we are replete with redundancy: if any one physiological variable is distorted by acute disease, there is an abundance of other systems (including not just physical systems, but social systems) to keep us clinically well. For example: a 20 -year-old with a broken leg uses crutches to offload pressure to other limbs and can usually carry out regular daily activities with minimal disruption, perhaps with the aid of a doting mother. A 20-year-old can withstand the sleep deprivation, untreated pain, bad hospital food and lack of hand washing that are part of routine care. A frail older person might not.

As we age, there is wear and tear on our systems, the cost of which is reduced redundancy. In an airplane, if systems are not maintained, redundancy is lost and suddenly a minor mechanical error can result in catastrophe. The critical clinical consideration is this: you as the passenger remain blind to the myriad minor mechanical failures that have precipitated such a catastrophe. Clinically, you recognise critical loss of redundancy in an airplane only when the highest order function of the airplane has failed: it can no longer get to your destination. When humans become frail, the clinical picture is also the result of failure of highest order functions (i.e. the most complex things we do which include walking, cognitive multitasking, using tools, and social awareness). Clinically, failure in walking appears as falls; failure in cognitive multitasking appears as delirium or confusion; failure to 'use tools' appears as functional decline; and failures of social awareness appear as incontinence, social withdrawal and other behavioural issues.

This analogy not only provides a construct by which to contextualise the most common clinical presentations in frail older adults, it provides an opportunity for the clinician to view delirium, falls and functional decline (which can be thought of as failures of such high order, integrative functions as conscious thought, walking and environmental manipulation) as opportunities to measure and manage frailty. In this way, these disease presentations can be related to frailty. Frailty in this view is less another geriatric syndrome than a state that predisposes to these disease presentations.

FIGURE I An analogy to enhance understanding of frailty.

that behaves in predictable ways across populations and ages. The $\mathrm{Fl}$ is measured by comparing the ratio of health deficits present within an individual to possible health deficits, using a pre-specified list of health conditions. The $\mathrm{Fl}$ allows inclusion of any health deficit providing that a minimum of 30 deficits in total are included and that each deficit is: associated with adverse health outcomes; increases in prevalence with age at least into the tenth decade; has a prevalence of at least $1 \%$ in the population; and does not saturate (e.g. does not become universal by age <85). The FI approach is robust: it has been widely studied across populations with differing sets and numbers of deficits included (from as few as 31 to as many as 100) and predicts survival, the risk of disease progression, the need for institutionalisation and the use of healthcare services. ${ }^{4}$ The index value generally increases at about 0.03 points per year of life and there appears to be a reproducible proportion of deficits (approximately 0.7) beyond which survival is not possible. One of the challenges of the $\mathrm{Fl}$ is that because at least 30 items of health information are required in its calculation, in some clinical settings its feasibility is
TABLE I Clinical assessment of Fried's frailty phenotype ${ }^{2}$

\begin{tabular}{|c|c|c|}
\hline Item & Type of measure & Criteria \\
\hline $\begin{array}{l}\text { Walking } \\
\text { speed }\end{array}$ & $\begin{array}{l}\text { Timed I5 foot } \\
\text { (5 metre) walk }\end{array}$ & $\begin{array}{l}\text { Slowest } 20 \% \text { by } \\
\text { gender and height }\end{array}$ \\
\hline Grip strength & Dynanometer & $\begin{array}{l}\text { Weakest } 20 \% \text { by } \\
\text { gender and body } \\
\text { mass index. }\end{array}$ \\
\hline Weight loss & Self-report & $\begin{array}{l}\text { Lost } 10 \text { lbs } \\
(4.5 \mathrm{~kg}) \text { in the past } \\
\text { year }\end{array}$ \\
\hline Fatigue & $\begin{array}{l}\text { Self-report: } \\
\text { 'trouble getting } \\
\text { going' }\end{array}$ & \\
\hline Activity level & $\begin{array}{l}\text { Self-report: } \\
\text { number of calories } \\
\text { expended }\end{array}$ & $\begin{array}{l}\text { Lowest } 20 \% \text {. } \\
\text { Males: } 383 \mathrm{kcals} / \text { week } \\
\text { Females: } 270 \mathrm{kcals} / \\
\text { week }\end{array}$ \\
\hline
\end{tabular}

reduced, so that another screening tool is also needed. Whether the advent of electronic medical records will make collation of multiple items that usually are available 
as burdensome a requirement as it now can be is of interest. $A$ recent Dutch report, which used an FI based on primary care records, appears to attest at least to the feasibility of the approach. ${ }^{6}$

One such screening tool is the Clinical Frailty Scale with which the assessor makes a judgment about the degree of a person's frailty based on clinical data, using what has now been modified as a 9-point ordinal scale (Table 2). In this approach, the health professional considers information about cognition, mobility, function and co-morbidities based on the history and physical examination to assign a frailty level from one (very fit) to nine (terminally ill with a life expectancy $<6$ months). This method is simple to administer and effectively estimates important outcomes, such as survival and institutionalisation. This makes it comparable to other methods (Table 3 ).

The history and examination sections provide guidance on how to assemble the necessary clinical information (i.e. the comprehensive geriatric assessment [CGA]) from which to use the Clinical Frailty Scale, but clinicians should also be aware of opportunities to recruit existing electronic medical record systems to simplify calculation of an FI using information gathered in the CGA. A greatly simplified approach, based on pictographs/icons for use in the pre-hospital setting is also under study. Several other frailty measures (e.g. the Groningen, ${ }^{8}$ Tilburg, ${ }^{9}$ and Edmonton ${ }^{10}$ scales) are available. These all appear to identify people at risk, so that issues of clinical sensibility, feasibility and familiarity will be influential in local settings.

\section{HISTORY}

The patient's history pertinent to frailty can be guided by the domains included in a standard CGA (Table 4). Usefully, the items in a CGA can be considered as health deficits and combined to score a frailty index, a so-called FI-CGA." The following points should be considered.

\section{Source of information}

In clinical scenarios where frailty is suspected, or likely, clinicians should aim to collect information on function, mobility and cognition from the patient and/or a collateral historian (a family member, caregiver, or someone who knows and sees the person regularly). Frailty is often associated with cognitive impairment. Most diseases that contribute to clinically significant cognitive impairment (dementia and delirium) are associated with reduced insight into the nature, extent and functional implications of cognitive deficits. Furthermore, the nature of frailty is that a person's health becomes increasingly dependent upon external support.The clinician's ability to establish early, empathetic
TABLE 2 The Clinical Frailty Scale

\begin{tabular}{|l|l|l|}
\hline Item & Description & Details $^{6}$ \\
\hline I & Very fit & $\begin{array}{l}\text { Robust, active, energetic, well- } \\
\text { motivated, and fit. Commonly } \\
\text { exercise regularly }\end{array}$ \\
\hline 2 & Well & $\begin{array}{l}\text { Without active disease but } \\
\text { less fit than category I }\end{array}$ \\
\hline 3 & Managing well & $\begin{array}{l}\text { Disease symptoms are well- } \\
\text { controlled compared with } \\
\text { those in category 4 }\end{array}$ \\
\hline 4 & $\begin{array}{l}\text { Apparently } \\
\text { vulnerable }\end{array}$ & $\begin{array}{l}\text { Although not frankly } \\
\text { dependent, commonly } \\
\text { complain of being slowed up } \\
\text { or have disease symptoms }\end{array}$ \\
\hline 5 & Mildly frail & $\begin{array}{l}\text { Limited dependence on others } \\
\text { for IADLs }\end{array}$ \\
\hline 6 & Moderately frail & $\begin{array}{l}\text { Help is needed with BADLs } \\
\text { and IADLs }\end{array}$ \\
\hline 7 & Severely frail & $\begin{array}{l}\text { Completely dependent for all } \\
\text { BADLs and IADLs }\end{array}$ \\
\hline 8 & Very severely frail & $\begin{array}{l}\text { Completely dependent, } \\
\text { approaching end of life. Could } \\
\text { not recover from even a } \\
\text { minor illness }\end{array}$ \\
\hline $\begin{array}{l}\text { IADLs= instrumental activities of daily living: banking, } \\
\text { transportation, cooking, cleaning, medication management, } \\
\text { shopping. BADLs= basic activities of daily living: feeding, } \\
\text { bathing, dressing, toileting, ambulation. }\end{array}$ \\
\hline & Terminally ill & $\begin{array}{l}\text { Life expectancy <6 months } \\
\text { but not otherwise frail. }\end{array}$ \\
\hline 9 & &
\end{tabular}

relationships with caregivers is critical to effective care planning. In any case, the point of the $\mathrm{Fl}$ is not to record patients' or carers' impression in the form of self-rated questionnaires, but to adjudicate the information, using clinical judgment, to provide valid data so that the health state of the patient can best be quantified.

\section{Timeline}

For each health domain (including cognition, function and mobility), the clinician should gather information about three periods in time.

The present: For many people, an assessment takes place during a health crisis when their health status is not at baseline. They may be in hospital, recently admitted to a long-term care facility, or undergoing treatment for a specific disease, such as congestive heart failure or pneumonia. Even fit people can look frail in those circumstances, so understanding the timeline is crucial.

Baseline: Most frail older adults experience a very gradual decline in function that is punctuated by acute decline associated with acute illness and subsequent improvement. Their 'baseline' refers to their 'usual' health. For most people, this is sometime within the last 2-4 weeks; for those with prolonged hospital stays, it 
TABLE 3 A comparison of three validated measures of frailty

\begin{tabular}{|c|c|c|c|c|}
\hline & $\begin{array}{l}\text { Description and } \\
\text { classification }\end{array}$ & $\begin{array}{l}\text { Outcomes (hazard } \\
\text { ratio and } 95 \% \\
\text { confidence interval } \\
\text { for death and } \\
\text { institutionalisation } \\
\text { respectively) }\end{array}$ & Pros & Cons \\
\hline $\begin{array}{l}\text { Fried's Frailty } \\
\text { Phenotype }\end{array}$ & $\begin{array}{l}\begin{array}{l}\text { Frail }=>1=3 \\
\text { characteristics }\end{array} \\
\begin{array}{l}\text { Pre-frail }=>1=2 \\
\text { characteristics }\end{array} \\
\text { Robust = none }\end{array}$ & $\begin{array}{l}1.17(1.13-1.20) \\
1.27(1.19-1.35)\end{array}$ & $\begin{array}{l}\text { Four of the five items are } \\
\text { objective (performance } \\
\text { can be measured). } \\
\text { Extensively validated to } \\
\text { predict health outcomes. } \\
\text { Correlation with } \\
\text { physiologic markers of } \\
\text { poor health outcomes } \\
\text { including haemoglobin and } \\
\text { pro-inflammatory markers. }\end{array}$ & $\begin{array}{l}\text { Misclassification. } \\
\text { Lack of consensus } \\
\text { regarding nature and } \\
\text { number of items. } \\
\text { Does not stage degrees } \\
\text { of frailty. }\end{array}$ \\
\hline $\begin{array}{l}\text { Clinical } \\
\text { Frailty Scale }\end{array}$ & $\begin{array}{l}\text { Classification on } \\
\text { ordinal scale (Table } \\
\text { 2) according to global } \\
\text { clinical assessment }\end{array}$ & $\begin{array}{l}\mathrm{I} .30(1.27-1.33) \\
\mathrm{I} .46(1.39-1.53)\end{array}$ & Clinically feasible. & $\begin{array}{l}\text { Requires additional data } \\
\text { on feasibility and validity in } \\
\text { clinical settings. }\end{array}$ \\
\hline Frailty Index & $\begin{array}{l}\text { Number of health } \\
\text { deficits present/ } \\
\text { number of possible } \\
\text { health deficits }\end{array}$ & $\begin{array}{l}1.26(1.24-1.29) \\
1.56(1.48-1.65)\end{array}$ & $\begin{array}{l}\text { Precise measurement. } \\
\text { Reproducible across } \\
\text { populations and disease } \\
\text { states. }\end{array}$ & $\begin{array}{l}\text { Cumbersome to use in } \\
\text { clinical settings. }\end{array}$ \\
\hline
\end{tabular}

may be longer. An understanding of baseline health is critical because, together with frailty, it helps to frame expectations for recovery. For example, many people with mild frailty will experience a complete clinical recovery from acute illnesses (e.g. pneumonia) and exacerbations of chronic illnesses (heart failure, chronic obstructive pulmonary disease). However, in moderate to severe frailty, it becomes more difficult to re-achieve baseline function. Baseline status of cognition, mobility and function are used to categorise frailty using the Clinical Frailty Scale.

Over the last several months: After establishing current and baseline health, you can widen your scope to look for indications of increasing frailty such as:

- Gradual loss of independence in several domains of function;

- Repeated health crises such as hospital visits and emergency department visits;

- Failure to maintain health at home: weight loss, increasing social isolation, declining mobility and impaired activities of daily living.

\section{Comprehensive Geriatric Assessment}

The CGA provides a template of those areas of the clinical history most pertinent to understanding the overall health status of an older adult (Figure 2). Within these domains, cognition, mobility and function emerge as primary indicators of health because they demonstrate features of state variables: that is to say they provide an indication of the overall health of the individual.

\section{Physical examination}

The physical examination in frailty should build upon information gathered regarding domains of functional loss or ongoing symptom burden and risks for poor health outcomes, such as falls. Beyond the standard physical examination in a fit older adult, the examination of the frail older adult should include:

\section{Vital signs}

- Evaluation for orthostatic hypotension

\section{Head and neck}

- Objective cognitive assessment

- Corrected visual acuity and fields

\section{Cardiovascular/respiratory/abdomen}

- Evaluation for fluid overload, stenotic heart valve lesions, or peripheral vascular disease, hard stool in bowel or rectum, full bladder 
TABLE 4 Outline for a standard comprehensive geriatric assessment ${ }^{\prime \prime}$

\begin{tabular}{|c|c|c|}
\hline $\begin{array}{l}\text { Health } \\
\text { domain }\end{array}$ & $\begin{array}{l}\text { Subjective } \\
\text { assessment } \\
\text { (includes the } \\
\text { nature, extent, } \\
\text { and functional } \\
\text { implications of } \\
\text { the deficits) }\end{array}$ & $\begin{array}{l}\text { Objective } \\
\text { assessment }\end{array}$ \\
\hline $\begin{array}{l}\text { Cognition and } \\
\text { mood }\end{array}$ & $\begin{array}{l}\text { Deficits in cognitive } \\
\text { domains including } \\
\text { short-term memory, } \\
\text { language, executive } \\
\text { function, orientation } \\
\text { and attention. } \\
\text { History of prior } \\
\text { or current mood } \\
\text { symptoms or } \\
\text { disorders including } \\
\text { depression and } \\
\text { anxiety. }\end{array}$ & $\begin{array}{l}\text { Selection of most } \\
\text { appropriate tool } \\
\text { depends upon the } \\
\text { clinical setting. }\end{array}$ \\
\hline Mobility & $\begin{array}{l}\text { Deficits in ability to } \\
\text { transfer or ambulate } \\
\text { and need for } \\
\text { assistive devices. } \\
\text { History of falls. }\end{array}$ & $\begin{array}{l}\text { Observed transfer } \\
\text { from sitting to } \\
\text { standing position. } \\
\text { Ambulating across } \\
\text { room and back. } \\
\text { Timed 'up and go'. }\end{array}$ \\
\hline Function & $\begin{array}{l}\text { Deficits in } \\
\text { instrumental } \\
\text { activities of daily } \\
\text { living (IADLs) or } \\
\text { basic activities of } \\
\text { daily living (BADLs). }\end{array}$ & $\begin{array}{l}\text { Observation of } \\
\text { functional abilities } \\
\text { is time and } \\
\text { resource intensive } \\
\text { and is usually } \\
\text { unnecessary for } \\
\text { achieving an overall } \\
\text { understanding of } \\
\text { function. }\end{array}$ \\
\hline Social health & $\begin{array}{l}\text { Living arrangements, } \\
\text { relationship } \\
\text { with caregiver } \\
\text { (frequency of } \\
\text { contact, reliability), } \\
\text { social engagement, } \\
\text { substance use and } \\
\text { abuse. }\end{array}$ & \\
\hline $\begin{array}{l}\text { Co- } \\
\text { morbidities }\end{array}$ & $\begin{array}{l}\text { Details of prior and } \\
\text { current medical and } \\
\text { surgical issues. }\end{array}$ & \\
\hline Medications & $\begin{array}{l}\text { Dose and schedule } \\
\text { of medications } \\
\text { associated with each } \\
\text { co-morbidity. }\end{array}$ & \\
\hline $\begin{array}{l}\text { Health } \\
\text { attitude }\end{array}$ & $\begin{array}{l}\text { Ask the patient: } \\
\text { 'How do you feel } \\
\text { your health is } \\
\text { compared to other } \\
\text { people your age?' }\end{array}$ & \\
\hline
\end{tabular}

\section{Musculoskeletal}

- Evidence of joint deformities, reduction in muscle bulk, strength (particularly proximal strength suggestive of deconditioning) or active range of motion

- Observation of patient transferring from sitting to standing position, ambulating across examination room, turning and returning to seat

\section{Skin}

- Evidence of pressure or vascular ulcers, particularly on the feet

\section{Neurological}

- Screening examination for lateralising deficits to suggest prior strokes

- Screening examination for parkinsonism

- Evaluation for paratonia

- Evaluation for peripheral neuropathy, particularly in lower extremities

\section{Investigations}

Given the broad range of health deficits that can contribute to frailty, as well as the non-specific clinical presentations (Figure I) that characterise acute illness in frailty (delirium, falls, functional decline), investigations should be tailored to the results of the history and physical examination, with additional attention to metabolic or physical deficits arising as adverse reactions to medications.

\section{Management}

The results of a diagnosis and assessment of the extent of frailty should be used to inform the clinical presentation and care plan in the following ways:

\section{Reconciliation of clinical presentation with underlying frailty}

Seasoned clinicians in geriatric medicine may recall 'the geriatric giants' (characterised by such disease presentations as immobility, incontinence, instability and impaired intellect) a phrase coined by Bernard Isaacs, one of the forefathers of the discipline, to remember the most common presentations of older adults. ${ }^{12} \mathrm{~A}$ related concept is that of 'atypical disease presentation': the idea that older adults tend to present with symptoms that are seemingly unrelated to the primary organ in which the disease is occurring. For example, a frail older adult with bacterial pneumonia may present with falls, and may not have the typical cough, fever, or elevation in white blood cell count that commonly heralds pneumonia in younger adults. For a clinician newly armed with an understanding of frailty, it will follow that atypical disease 
I. Cognition: Subjective account of the nature, timeline, extent and functional implications of cognitive deficits from the collateral historian should be combined with objective measures of cognition (the selection of which may depend on the clinical setting) to formulate an understanding of whether cognitive deficits are acute (such as delirium) or most consistent with a chronic progressive disease (such as dementia).

2. Mobility: An understanding of an individual's present and baseline mobility includes their ability to transfer, ambulate and perform manoeuvres that require balance (use of stairs, ability to reach for objects). A history of falls may signify increasing frailty or acute illness depending on the timeline.

3. Function: A subjective account of the nature, timeline and extent of deficits specific to activities of daily living (Table 4) forms the basis of functional assessment. The nature of the deficit is particularly important to note as deficits may be secondary to limitations in cognitive or physical abilities or may be secondary to choice (i.e. the person has never driven or managed his or her own finances). Functional domains exist on a hierarchical scale whereby instrumental activities of daily living (IADLs) tend to be affected before basic activities of daily living (BADLs).

4. Social health: Information about living circumstances, relationship status (married, widowed, single, divorced), caregiver involvement, substance use and abuse, social activities and engagement form the basis of a screening evaluation for social health.

5. Co-morbidities: The 'past medical history', including details of the stage and severity of ongoing medical issues (congestive heart failure, renal disease, etc.) provide an indication of overall disease burden and symptom control.

6. Medications: An up-to-date list of all medications (including over-the-counter or complementary/ alternative medicines [CAMs]) helps further clarify the disease and symptom burden as well as providing opportunities for optimisation of medical therapy and understanding present symptoms as possible manifestations of drug side-effects or interactions.

FIGURE 2 Primary domains of health.

presentations are manifestations of the failure of highest order functions (Figure I) and therefore indicate underlying frailty. Such presentations in older adults indicate acute medical illness and require urgent and thorough investigation. In as much as 'atypical' disease presentations may be the norm for frail older adults, terminology favouring specific descriptions (e.g. 'this patient has delirium and now cannot walk without assistance') is preferred. As noted in Figure I, this understanding of frailty as a graded state, the severity of which depends on the degree to which deficit accumulation impairs high order functions sees it as distinct from a geriatric syndrome. Even so, we recognise that on such distinctions (which go back to original, nearly simultaneous publications by now competing groups) $)^{13}$ operational and sometimes conceptual confusion can result. For those so interested, recent detailed expositions of frailty in relation to deficit accumulations, in comparison with alternate approaches, and its consequences for the practice of geriatric medicine are available. ${ }^{4,13}$

\section{Careful application of evidence-based medicine}

Ageing is associated with accumulation of health deficits. By its nature, frailty affects multiple systems, requiring complex responses, such as exercise and comprehensive geriatric assessment. ${ }^{14}$ Unfortunately, the specialised nature of modern healthcare means that we often are asked to apply clinical practice guidelines to improve one health condition that might well be to the detriment of others. ${ }^{15}$ This is because the focus on single conditions means that frail older adults, for whom all diseases are common, as are the adverse effects of treatments, are commonly excluded from clinical trials. ${ }^{16}$ Perhaps the most vital value of recognising frailty is that it provides the clinician with an opportunity to address the person's overall health. For example, a non-steroidal antiinflammatory drug (NSAID) with proven symptomatic benefits in osteoarthritis might (when prescribed as part of the application of a clinical practice guideline) precipitate fluid retention and heart failure in a frail older adult. That is why the specialty of geriatrics has evolved sayings such as 'start low, go slow'. This is not simply codified common sense, but a rational response to patients' complexity. Indeed, it is a principle of a complex system that any intervention will have multiple effects: 'you can't just do one thing at once'.

\section{Opportunities to discuss prognosis}

Frailty is associated with a higher risk of poor health outcomes after health interventions, including prolonged hospital stay, delirium, permanent functional decline, need for long-term care, adverse drug reactions and death. In quantifying risk in relation to the extent of deficit accumulation, the $\mathrm{FI}$ lends predictive (criterion) validity to the notion that every frail older adult will have a unique collection of health deficits and symptoms that contribute to frailty. The uncertainty inherent in this 
variability, combined with the complexity that comes with multiple interacting disease pathologies often causes clinicians to avoid discussions about prognosis, but the vulnerability and shorter life expectancy associated with frailty means frail older adults may stand to benefit from receiving information about their prognosis more than any other group. Several clinical truths can be useful in structuring discussions around prognosis in frailty:

I. Most frail older adults with multiple co-morbidities have never had the opportunity to discuss their overall health and prognosis with a clinician.

2. Provision of information about what to expect with disease progression can affect the choices people make.

3. Although the nature and timing vary considerably, the presence of frailty indicates that an individual will experience one or more health crises in the future necessitating emergency care. $A$ health crisis could be the result of sudden worsening of a preexisting co-morbidity or development of a new health issue.

4. Due to the higher prevalence of baseline dementia (and greater chance of delirium during acute illness) in frailty, very commonly frail individuals will not be fully able to direct their own care at the time of a health crisis. Early involvement of a caregiver in care planning discussions helps ensure that advance directives are followed.

In contrast, care of older adults who are not frail typically is straightforward and greatly benefits from practice guidelines focused on single illnesses. Care of frail older adults, especially when they are acutely ill is more complex. Such care requires a skill set that can embrace this complexity and not seek to reduce it to single problems, on a problem list, treated one at a time. A range of research opportunities remains in relation to how to introduce feasible means of doing this.

\section{Opportunities to optimise use of healthcare resources}

In addition to prevention, our healthcare system faces challenges in how it responds to the enormous burden of caring for those with existing frailty. With the exception of younger people, those who require homecare services or long-term care are frail. Health services, like homecare, are ideally situated not only to compensate for failures of highest order functions by providing external backup systems, but to recognise frailty and offer programmes for frail older adults that are designed to enhance their understanding of their health and to plan for the future.

Conversely, although team-based care for older adults is a well-used if not well-studied approach, older adults who are not frail, generally do not require multifaceted interventions such as those often prescribed for falls and greatly benefit from the application of clinical practice guidelines focused on single illnesses.

\section{Opportunities for intervention and research}

When complex systems fail, they often fail in their highest order function first. Thus in humans, impaired mobility represents failure in the high order function of upright bipedal ambulation. It conforms to the clinically sensible dictum that, as people become ill they move less easily and as they get better they move more easily. Translating this to a measurable tool can sharpen clinical reasoning regarding the clinical course (e.g.'Is my patient getting better?'). Clinical research that seeks to make such skill sets widely available offers a wide range of opportunities. Knowing which items in the tool kit of the geriatrician are most useful is likewise a rich area for future research.

\section{Highlights}

- The clinical definition of frailty has evolved significantly in the last 15 years, such that it can be reliably recognised and quantified in a number of ways.

- Clinical details, including timeline of changes in cognition, mobility and function are of particular importance in quantifying frailty in clinical settings.

- Frailty denotes vulnerability to poor health outcomes. Its presence should alert the clinician to opportunities to carefully weigh the risk/ benefit ratio of healthcare interventions and to discuss prognosis.

- Acute illness in frail older adults most often presents with failures of highest order functions of cognition, mobility, and function, manifested clinically as delirium, falls and functional decline, respectively.

- Research opportunities to refine the role of frailty in clinical decision-making abound.

\section{REFERENCES}

I Rockwood K, Fox RA, Stolee P et al. Frailty in elderly people: an evolving concept. CMAJ 1994; I50:489-95.

2 Fried LP, Tangen CM, Walston J et al. Frailty in older adults: evidence for a phenotype. J Gerontol A Biol Sci Med Sci 200I; 56:MI46-56. http://dx.doi.org//0.1093/gerona/56.3.MI46

3 Kulminski AM, Ukraintseva SV, Kulminskaya IV et al. Cumulative deficits better characterize susceptibility to death in elderly people than phenotypic frailty: lessons from the Cardiovascular Health Study. J Am Geriatr Soc 2008; 56:898-903. http://dx.doi. org/I0.IIII/j.I532-54I5.2008.0I656.x

4 Rockwood K, Mitnitski A. Frailty defined by deficit accumulation and geriatric medicine defined by frailty. Clin Geriatr Med 20II; 27:17-26. http://dx.doi.org/10.1016/j.cger.2010.08.008 
5 Mitnitski AB, Mogilner AJ, Rockwood K.Accumulation of deficits as a proxy measure of aging. Scientific World Journal 200I; I:323-36. http://dx.doi.org/I0.1 I00/tsw.2001.58

6 Drubbel I, de Wit NJ, Bleijenberg $\mathrm{N}$ et al. Prediction of adverse health outcomes in older people using a frailty index based on routine primary care data.J Gerontol A Biol Sci Med Sci 2012. http:// dx.doi.org/l 0. I093/gerona/gls I6I

7 Rockwood K, Song X, MacKnight C et al.A global clinical measure of fitness and frailty in elderly people. CMAJ 2005; I73:489-95. http://dx.doi.org/I0.1503/cmaj.05005I

8 Steverink N, Slaets JPJ, Schuurmans $\mathrm{H}$ et al. Measuring frailty development and testing of the Groningen Frailty Indicator (GFI). Gerontologist 200I; 4I:236-7.

9 Gobbens RJ, van Assen MA, Luijkx KG et al. The Tilburg Frailty Indicator: psychometric properties. J Am Med Dir Assoc 2010; I I:344-55. http://dx.doi.org/I0.1016/j.jamda.2009.II.003

10 Rolfson DB, Majumdar SR, Tsuyuki RT et al.Validity and reliability of the Edmonton Frail Scale. Age Ageing 2006; 35:526-9. http:// dx.doi.org//0.1093/ageing/afl04 I
I I Jones D, Song X, Mitnitski A et al. Evaluation of a frailty index based on a comprehensive geriatric assessment in a population based study of elderly Canadians. Aging Clin Exp Res 2005; 17:465-71.

12 Isaacs B. The challenge of geriatric medicine. Oxford: Oxford University Press; 1992.

I3 Lacas A, Rockwood K. Frailty in primary care: a review of its conceptualization and implications for practice. BMC Med 20I2; 10:4. http://dx.doi.org/10.1 186/1741-7015-10-4

I4 Ellis G,Whitehead MA, Robinson D et al. Comprehensive geriatric assessment for older adults admitted to hospital: meta-analysis of randomized controlled trials. BMJ 20I I; 343:d6553. http://dx.doi. org/10.II36/bmj.d6553

I5 Theou O, Stathokostas L, Roland KP et al. The effectiveness of exercise interventions for the management of frailty: a systematic review. J Aging Res 201 I; 201 I:569194.

16 Lindley RI. Drug trials for older people.J Gerontol A Biol Sci Med Sci 2012; 67:I52-7. http://dx.doi.org/ I0.1093/gerona/glr065

\section{SELF-ASSESSMENT QUESTIONS}

I. In severely frail older adults, the application of clinical practice guidelines (CPGs) is challenging because:

Choose ONE answer

A. The number of years needed to treat may exceed life expectancy.

B. Frail older adults are often excluded from randomised clinical trials from which CPGs are created.

C. Guideline-based treatment of one health issue may make other health issues worse.

D. The adverse outcomes associated with overtreatment are immediate while the benefits may take years to achieve.

E. All of the above.

2. A major limitation of the frailty index method for measuring frailty is:

Choose ONE answer

A. That the selection of items to include in the index is influenced by the clinical setting.

B. That it has not been validated in large scale datasets.

C. That it is cumbersome to use in clinical practice.

D. That it is influenced by the underlying burden of chronic disease.

E. That there is a limit of 0.66 beyond which survival is not possible.
3. Mrs Jones has end-stage congestive heart failure that causes her to be short of breath while dressing. She requires assistance with bathing, meal preparation, cleaning, and depends upon others for all activities outside the home. According to the Clinical Frailty Scale, Mrs Jones is:

Choose ONE answer
A. Well.
B. Vulnerable.
C. Severely frail.
D. Moderately frail.
E. Mildly frail.

\section{Which of the following is not part of the Fried rules-based definition of frailty? \\ Choose ONE answer}
A. Sense of exhaustion.
B. Weight loss.
C. Weakness.
D. Needing help with daily activities.
E. Low physical activity.

\section{Which of the following outcomes has been shown} to be associated with frailty?

Choose ONE answer
A. Death.
B. Institutionalisation.
C. Adverse drug reactions.
D. Falls.
E. All of the above.

This paper was originally published as part of the Public Health module in the RCPE Online Continuing Medical Education Programme. Online CME, including the anwers to these questions, is available to Fellows and Members at: $h$ ttp://www.rcpe.ac.uk 